UCRL-ID-121808

L-19757-1

RECEIVED

OCT 131995

OSTI

\title{
Design of a Substrate Heater for Calcium Hydroxyapatite Coating by Pulsed Laser Ablation
}

Tenny Chang

Mark A. Havstad

July 24,1995

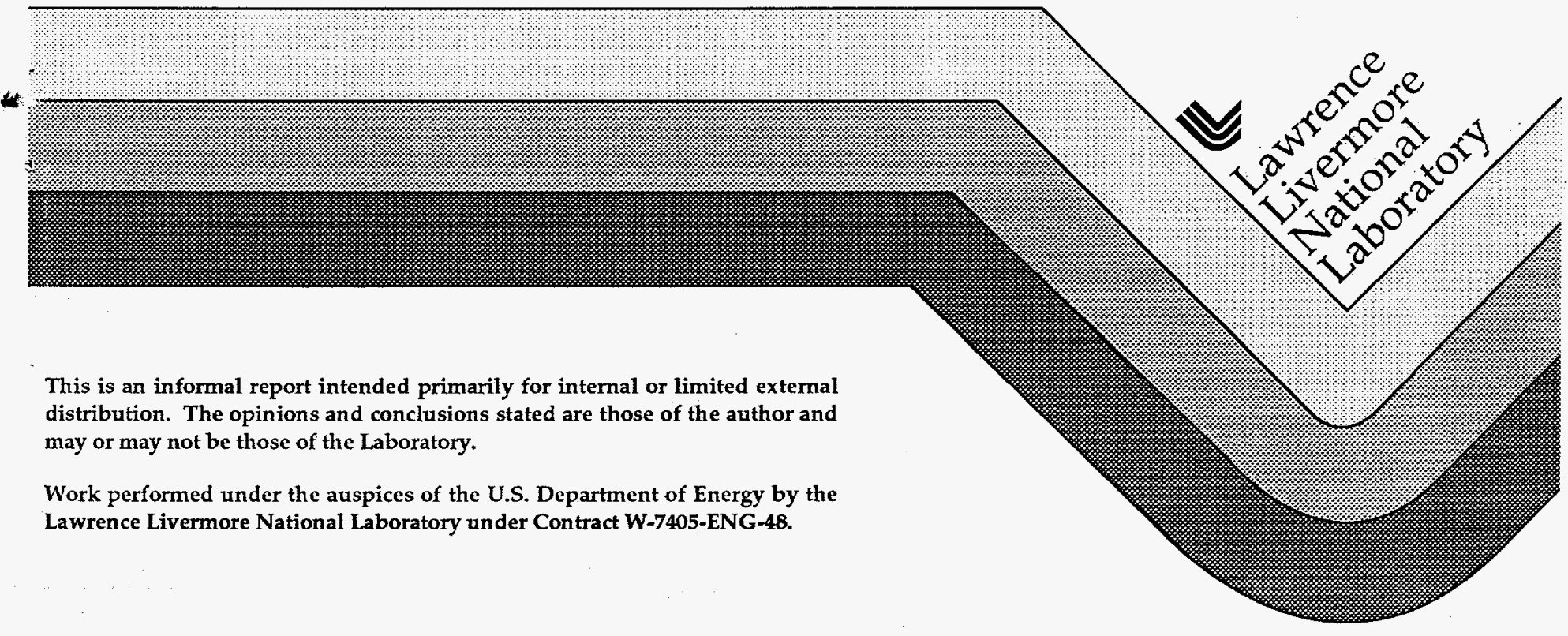

This is an informal report intended primarily for internal or limited external distribution. The opinions and conclusions stated are those of the author and may or may not be those of the Laboratory.

Work performed under the auspices of the U.S. Department of Energy by the Lawrence Livermore National Laboratory under Contract W-7405-ENG-48. 


\section{DISCLAIMER}

This document was prepared as an account of work sponsored by an agency of the United States Government. Neither the United States Government nor the University of California nor any of their employees, makes any warranty, express or implied, or assumes any legal liability or responsibility for the accuracy, completeness, or usefulness of any information, apparatus, product, or process disclosed, or represents that its use would not infringe privately owned rights. Reference herein to any specific commercial product, process, or service by trade name, trademark, manufacturer, or otherwise, does not necessarily constitute or imply its endorsement, recommendation, or favoring by the United States Government or the University of California. The views and opinions of authors expressed herein do not necessarily state or reflect those of the United States Government or the University of California, and shall not be used for advertising or product endorsement purposes.

This report has been reproduced directly from the best available copy.

Available to DOE and DOE contractors from the Office of Scientific and Technical Information P.O. Box 62, Oak Ridge, TN 37831

Prices available from (615) 576-8401, FTS 626-8401

Available to the public from the National Technical Information Service

U.S. Department of Commerce 5285 Port Royal Rd.,

Springfield, VA 22161

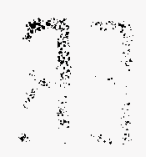




\section{DISCLAIMER}

Portions of this document may be illegible in electronic image products. Images are produced from the best available original document. 


\title{
Design of a Substrate Heater for Calcium Hydroxyapatite Coating by Pulsed Laser Deposition
}

\begin{abstract}
Calcium hydroxyapatite (HA) is the main chemical constituent of bone. When replacement hip joints are coated with this chemical, the body may be more likely to accept the artificial joint, forming new bone that bonds the joint to the original leg bone. HA deposited by laser ablation in vacuum adheres to the substrate better at high temperatures of up to $700^{\circ} \mathrm{C}$. This heater should be capable of uniformly heating to $700^{\circ} \mathrm{C}$ a silicon disk $150 \mathrm{~mm}$ in diameter.

The heater consists of two wire heating coils brazed into a disk of stainless steel, with tantalum shields on top and at the sides of the heater to minimize radiation loss. Three spring-rotation clamps at the bottom of the heater hold the substrate disk in place.
\end{abstract}

This report describes the heater and how it was developed, including design evolution and thermal modeling. Also, detailed information about parts is discussed.

\subsection{Introduction}

Calcium hydroxyapatite (HA) is the main chemical constituent of bone[1]. When replacement hip joints are coated with this chemical, the body is more likely to accept the artificial joint, forming new bone that bonds the joint to the original leg bone. HA deposited by laser ablation adheres to the substrate better at high temperatures of up to $700^{\circ} \mathrm{C}$. This heater should be capable of uniformly heating to $700^{\circ} \mathrm{C}$ a silicon disk $150 \mathrm{~mm}$ in diameter.

This heater will be used in a vacuum system with pressures less than $1 \times 10^{-7}$ torr. The copper vapor laser used for ablation operates with $200 \mathrm{~kW}$, at $4.4 \mathrm{kHz}$, and at wavelengths of 578 and $514 \mathrm{~nm}$.

The heater consists of two wire heating coils brazed into a disk of stainless steel, with tantalum shields on top and at the sides of the heater to minimize radiation loss. Three spring-rotation clamps at the bottom of the heater hold the substrate disk in place.

This report describes the heater and how it was developed, including design evolution and thermal modeling. Also, detailed information about parts is discussed. 


\subsection{Design Specifications}

- Heat $150 \mathrm{~mm}$ diameter disk

- Heat to maximum temp $700^{\circ} \mathrm{C}, \pm 10^{\circ} \mathrm{C}$ variation allowable

- Easy to use clamps for holding substrate

- Maximum width allowable 8 " to fit in vacuum chamber

- Voltage input under $120 \mathrm{~V}$

- Heater must attach to feedthrough shaft

- Works in vacuum better than $1 \times 10^{-7}$ torr.

\subsection{Thermal Modeling}

Thermal modeling was done in three steps, with control volumes decreasing in size, and increasing in complexity and physical effects modeled.

\subsection{Radiation Heat Transfer Only}

In the first step, the disk was analyzed as a single control volume to find the power input required to maintain the disk at $700^{\circ} \mathrm{C}$. Thus, the energy required is the sum of the radiation from the top of the heater and the radiation from the bottom of the heater, as shown by Figure 3.1.1.

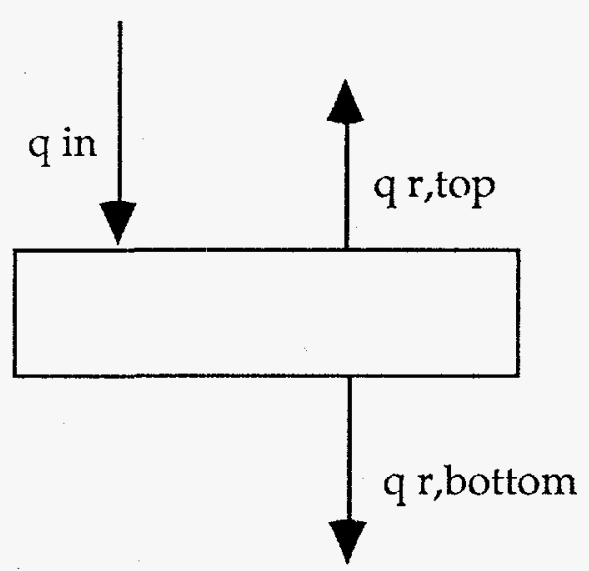

Figure 3.1.1 Whole disk as control volume.

$$
q_{\text {in }}=q_{r, \text { top }}+q_{r, \text { boutom }}
$$

This yielded an estimate of $320 \mathrm{~W}$, the power input required to maintain the disk at $700^{\circ} \mathrm{C}$. 


\subsection{1-D Radiation and Conduction}

In the next step, thermal transfer was modeled as one dimensional thermal conduction and radiation. The desired temperature of the bottom of the heater was set at $700^{\circ} \mathrm{C}$, with the temperature of the top of the heater and the power input adjusted until the conduction heat transfer equaled the radiation loss from the bottom of the heater.

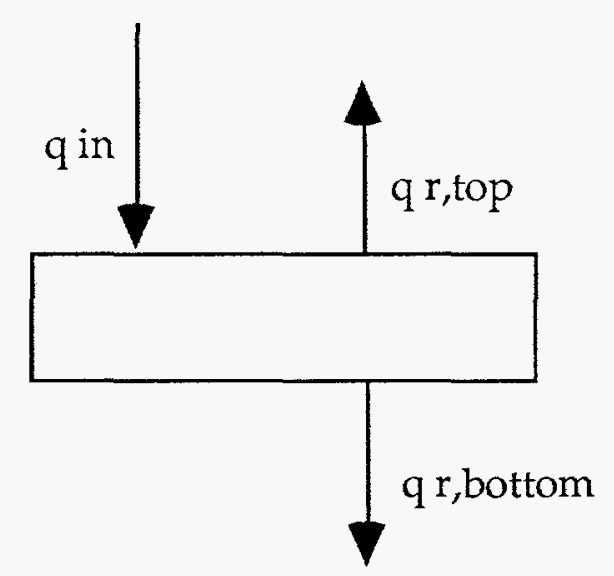

Figure 3.2.1 Entire disk as control volume.

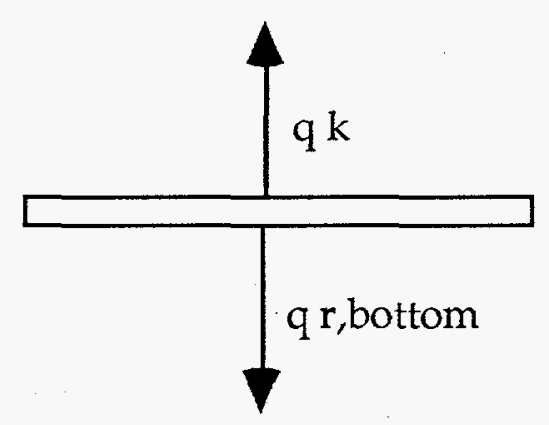

Figure 3.2.2 Bottom layer of disk as control volume.

$$
\begin{aligned}
& q_{i n}=q_{r, \text { top }}+q_{r, \text { bottom }} \\
& q_{k}=q_{r, \text { botom }} \\
& q_{k}=k A\left(T_{\text {top }}-T_{\text {bottom }}\right)
\end{aligned}
$$

This analysis provided a more exact estimate, $324.47 \mathrm{~W}$, of the power required to achieve $700^{\circ} \mathrm{C}$ on the bottom of the heater. Also, this gave us an estimate for how hot the top of the heater should be, $705^{\circ} \mathrm{C}$. 


\subsection{2-D Convection and Conduction}

A coil-shaped wire heater would best suit the goal to heat a circular substrate. Thus, the focus of the 2-D modeling was to determine a reasonable spacing between coils.

In this step, thermal transfer was modeled in two dimensions. The situation was set up as a block with a line heater on the upper left edge and convection on the top face. There was no heat transfer on the bottom and right faces because of planes of symmetry. Convection was used to approximate the radiation loss.

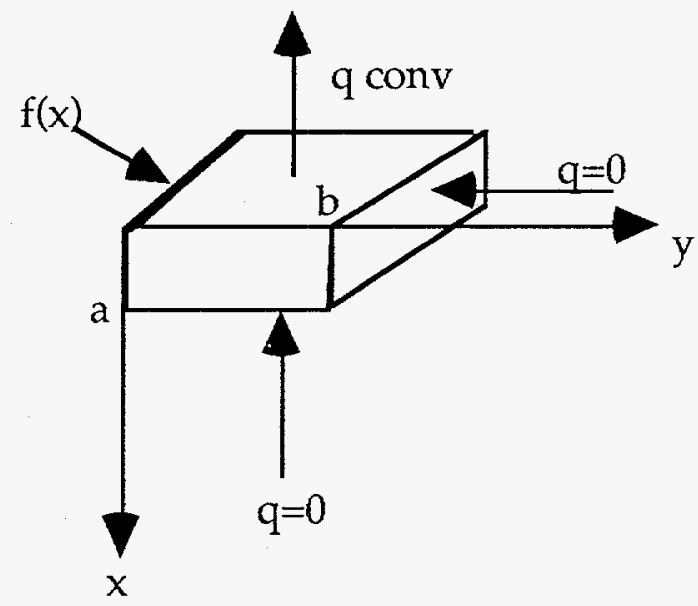

Figure 3.3.1 Diagram of 2-D analysis.

The temperature distribution of this situation was found in Conduction of Heat in Solids [2].

$$
T=\sum_{n=1}^{\infty} \frac{2\left(h^{2}+\alpha_{n}^{2}\right) \cos \left(\alpha_{n} x\right) \cosh \left(\alpha_{n}(b-y)\right)}{\left[\left(h^{2}+\alpha_{n}^{2}\right) a+h\right] \cosh \left(\alpha_{n} b\right)} \int_{0}^{a} f(x) \cos \left(\alpha_{n} x\right) d x
$$

where

$$
\begin{aligned}
& h=\frac{\text { convection coefficient }}{\text { conduction coefficient }} \\
& \alpha \tan (\alpha a)=h
\end{aligned}
$$

The eigenvalues $\alpha_{n}$ of the last equation were computed iteratively.

For the temperature distribution $f(x)$, we chose

$$
f(x)=\left(T_{\text {top }}-T_{\text {bottom }}\right) e^{-K x}+T_{\text {bottom }}
$$


which gives a sharp temperature peak at $\mathrm{x}=0$, with a drop-off to the temperature at the bottom of the heater. With $\mathrm{K}=8000$, the temperature drops quickly, as shown in the following graph:

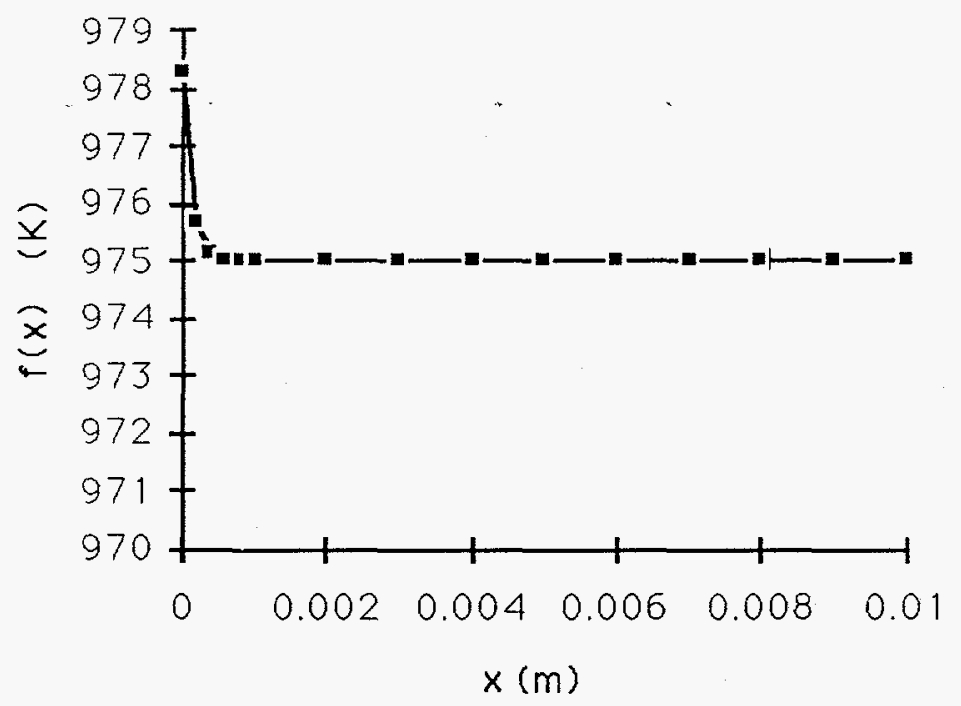

Figure 3.3.2 Heater temperature $f(x)$ vs. $x$.

The temperature distribution $T$ varied greatly depending on the equation used for the line heat source $f(x)$ at the top left of the block. However, for reasonable estimates of $f(x)$, this model showed that temperature gradients were low on the bottom of the heater surface $\left(.44^{\circ} \mathrm{C}\right)$, and that a heater coil spacing of $1 \mathrm{~cm}$ was reasonable. The graph below, giving the change in temperature across the top of the heater, shows the small temperature gradient.

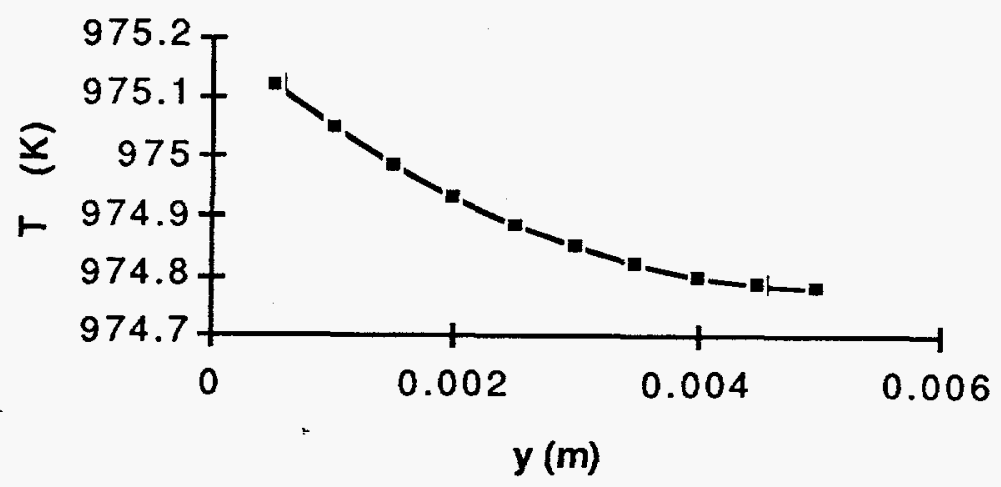

Figure 3.3.3 Temperature $\mathrm{T}$ vs. $\mathrm{y}, \mathrm{x}=0$. 


\subsection{Final Design}

\subsection{Heater}

Heater Body

In the final design, most parts, including the heater body, are stainless steel. Stainless steel has a fairly high conduction coefficient, $38 \mathrm{~W} / \mathrm{m} * \mathrm{~K}$ at $500^{\circ} \mathrm{C}$, and welds easily. Using a common material cuts down on cost, and makes obtaining parts easier. Also, because most of the parts are stainless steel, there is less likelihood of electrochemical reactions between the parts. The heater body is a 6 " diameter disk, $1 / 2$ " inch thick, with an $1 / 8^{\prime \prime}$ deep spiral groove cut for the heaters.

\section{Shields}

Shields are positioned on the sides and top of the heater to minimize radiation heat loss. Tantalum was chosen for the shields because of its low vapor pressure and ability to withstand high temperatures. $1 / 4$ " outer diameter ceramic tubing is used around the screws to serve as spacers for the shields and to minimize conduction heat transfer.

\section{Heating Coil}

Originally, we wanted one continuous coil heater to fit in a groove in the heater body. However, this specification was too rigorous for the heaters on the market. Instead, we chose to have two separate coil heaters, both from Watlow, $1 / 8$ " wire diameter, 47" long, able to take up to $120 \mathrm{~V}$ and $235 \mathrm{~W}$. One heats the region from diameter 1 " to $3.25^{\prime \prime}$, and the second coil heats from diameter 3.5" to $5.75^{\prime \prime}$.

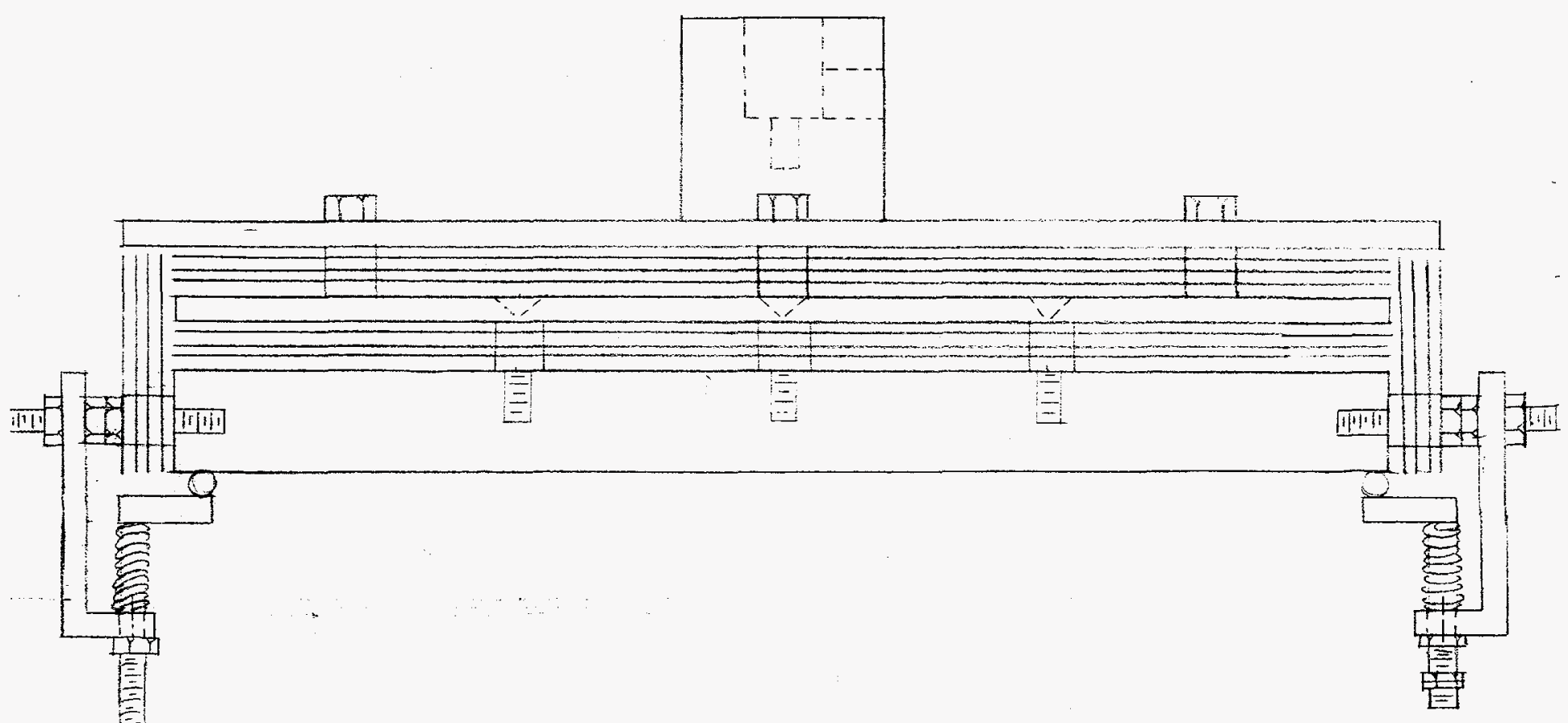

Figure 4.1 Picture of heater assembly. 


\subsection{Spring-Rotation Clamp}

The spring-rotation clamp was chosen for its versatility. The clamp can be removed from the substrate by pulling down on the lower large nut, then rotating. The height of the clamps can be adjusted by turning the nut on the 4-40 stud. Because it is "powered" by a compression spring (3/16" outer diameter, $1 / 2$ " long, $.184^{\prime \prime}$ wire diameter), this clamp is secure. The clamp contacts the substrate with the $1 / 8^{\prime \prime}$ stainless steel ball, ensuring that the substrate will not be damaged when the clamp is being moved, in case the operator fails to pull down on the clamp before rotating it.

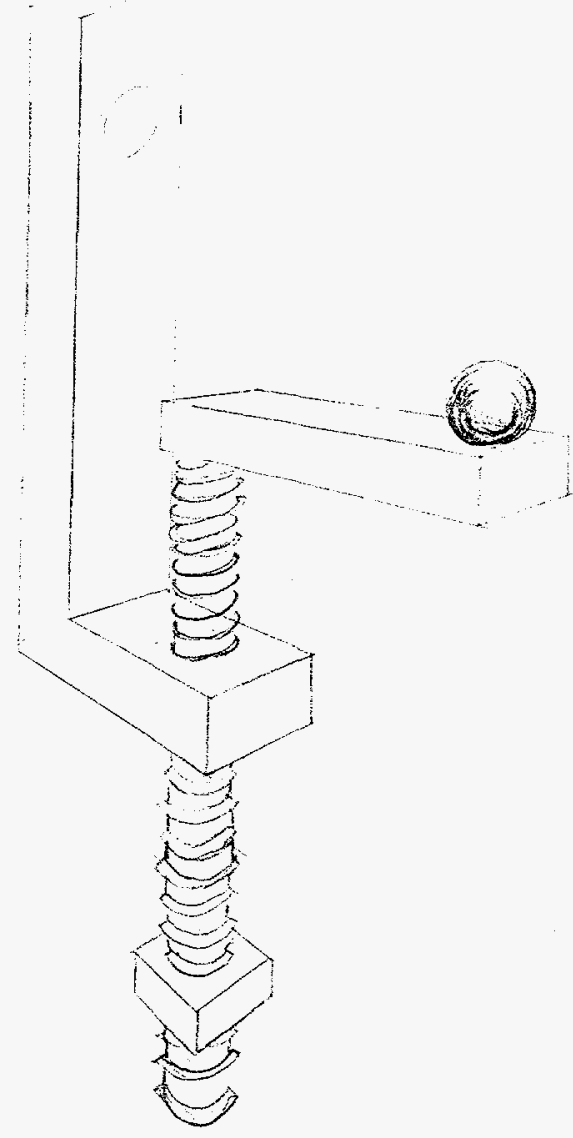

Figure 4.2 Picture of clamp assembly. 


\subsection{Detail Drawings}

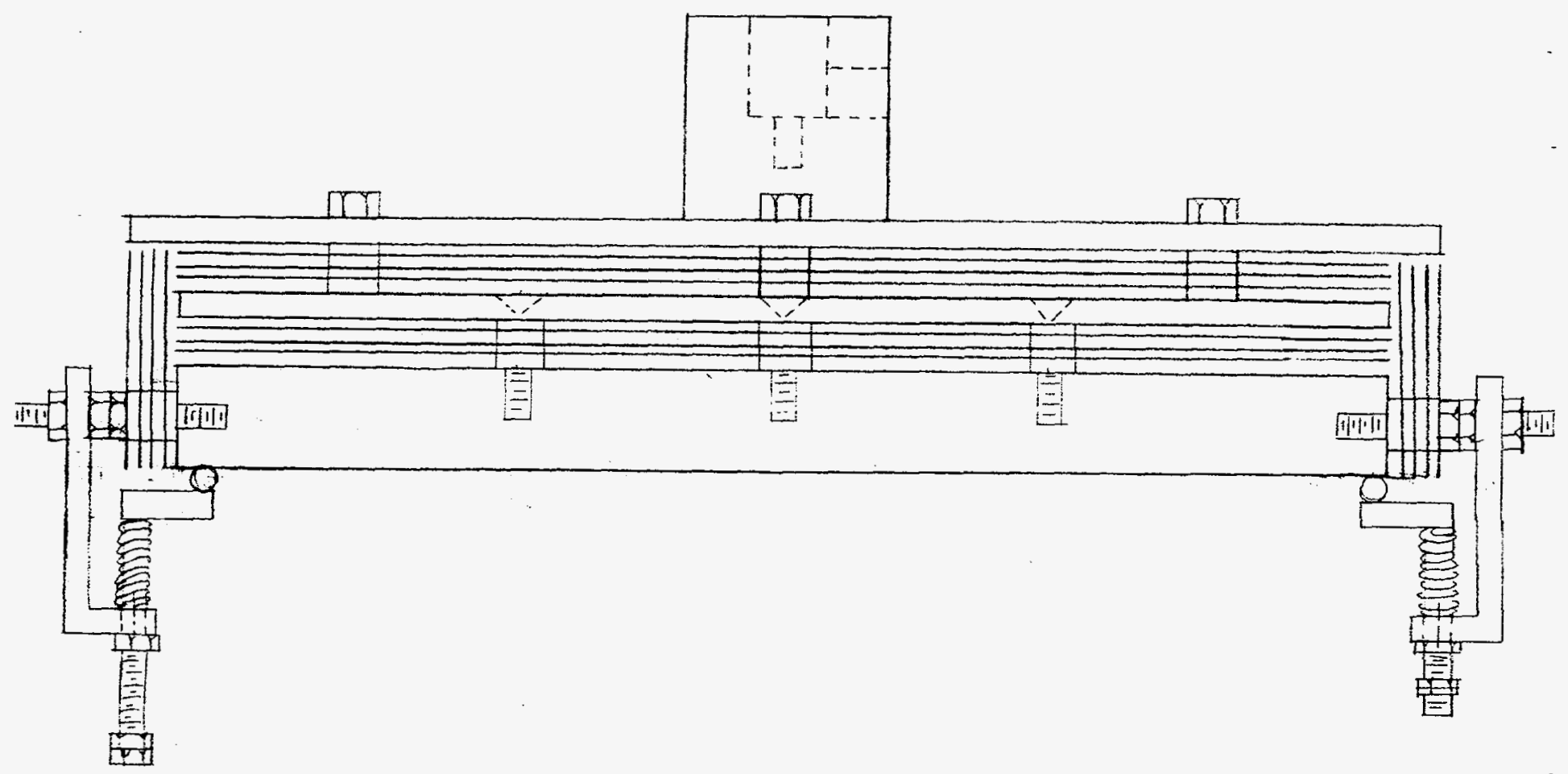

Figure 4.3.1 Assembly drawing. 
INCHES, SCALE 1.0

1 STANLESS ST.
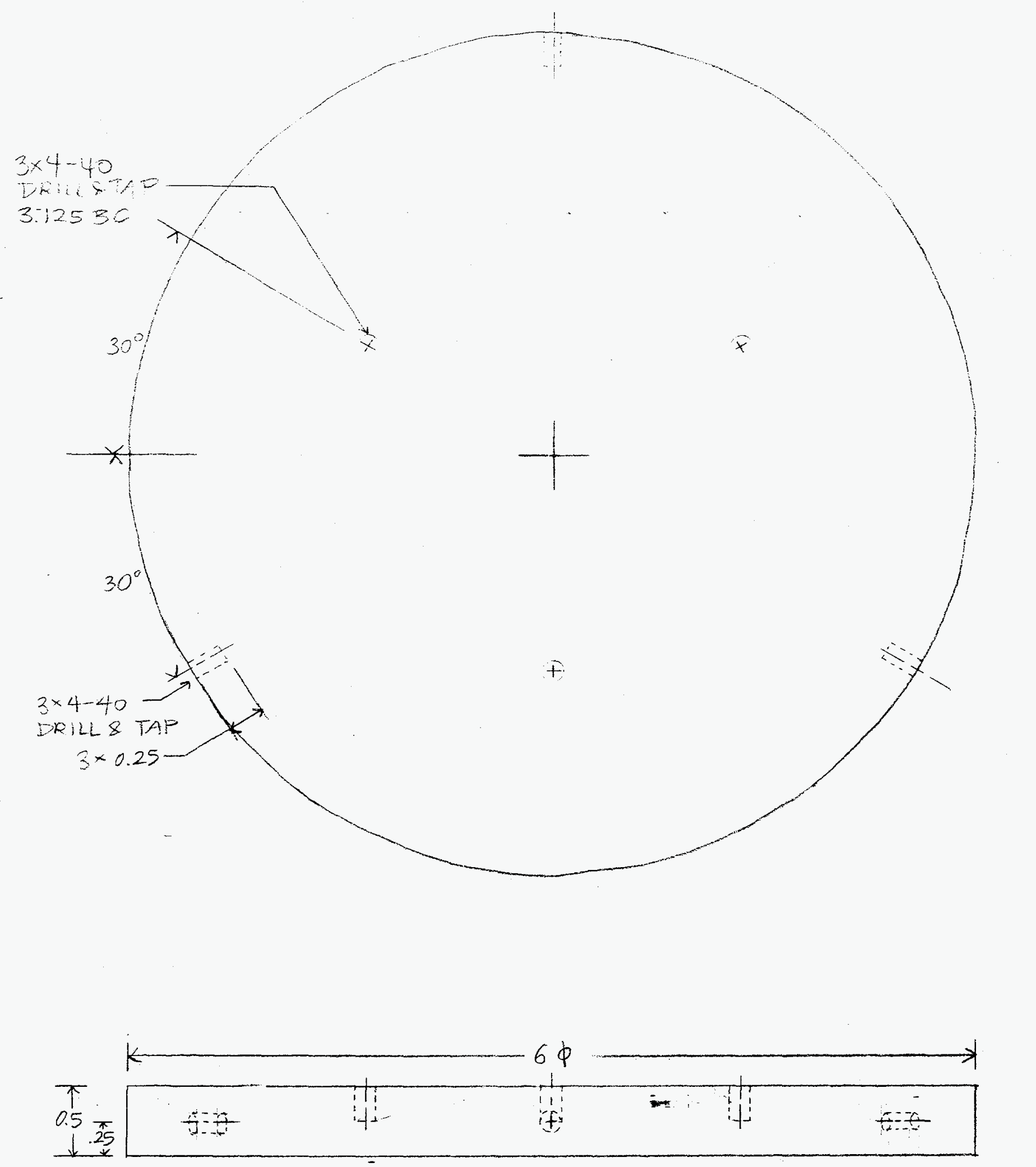

Figure 4.3.2 Heater body. 
WCHES, SCALE D.O

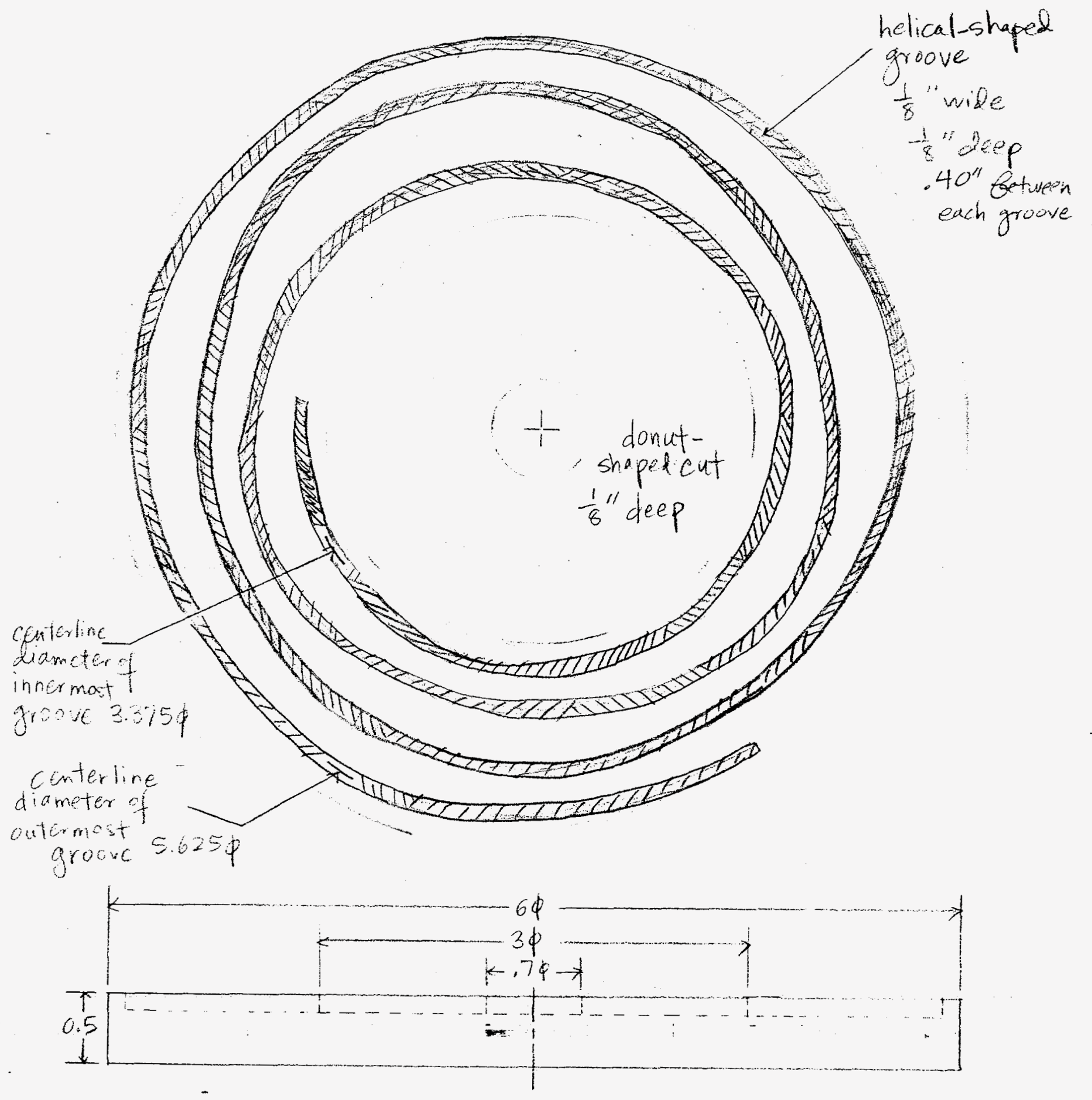

Figure 4.3.3 Heater groove. 
Whates.580

(3) $\frac{1}{5}: 95$
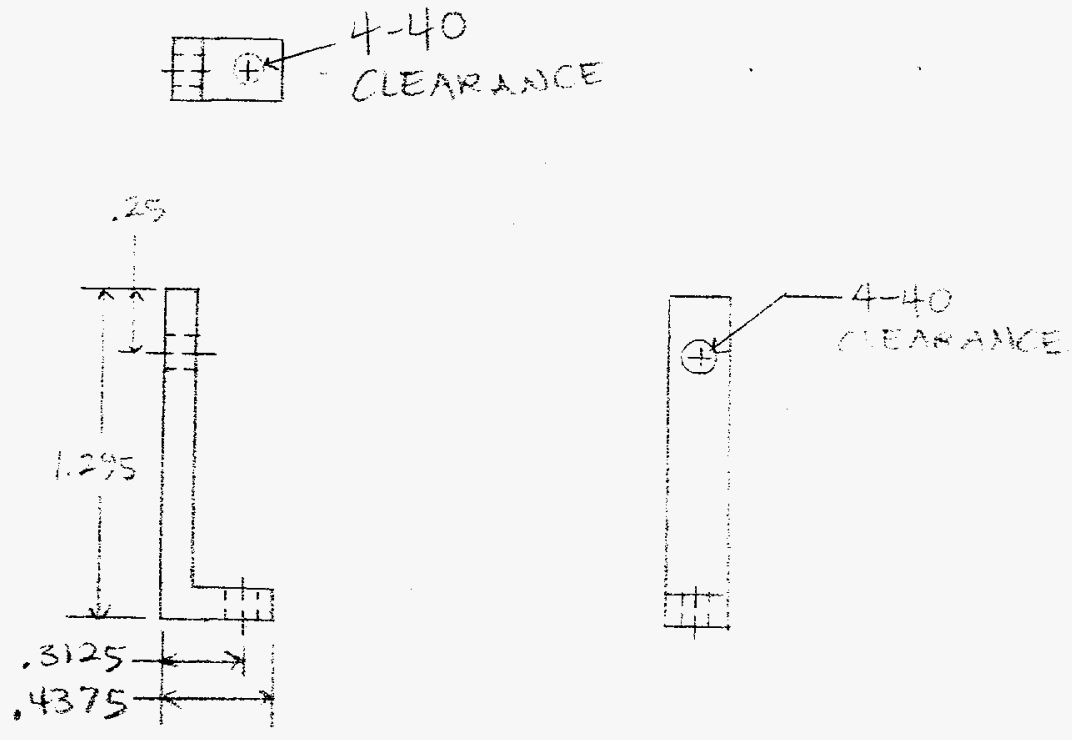

INCHES, SCALE 1.0

Figure 4.3.4 Clamp - part I.

(3) $-\frac{1}{8} " 55 T$
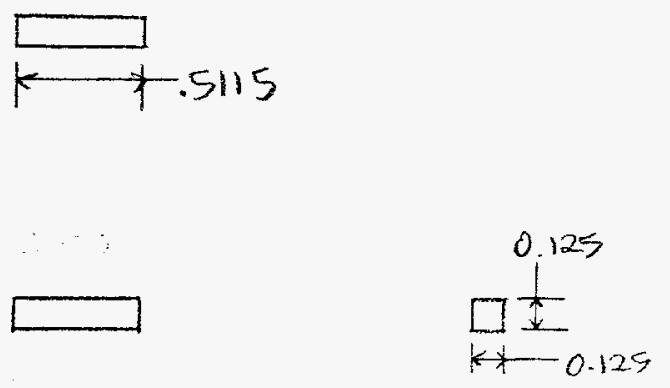

Figure 4.3.5 Clamp - part II. 
INCHES

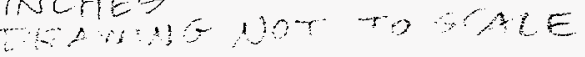

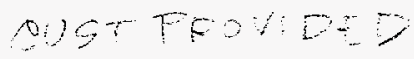

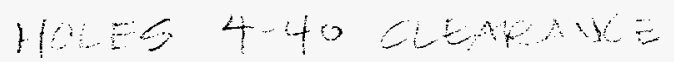
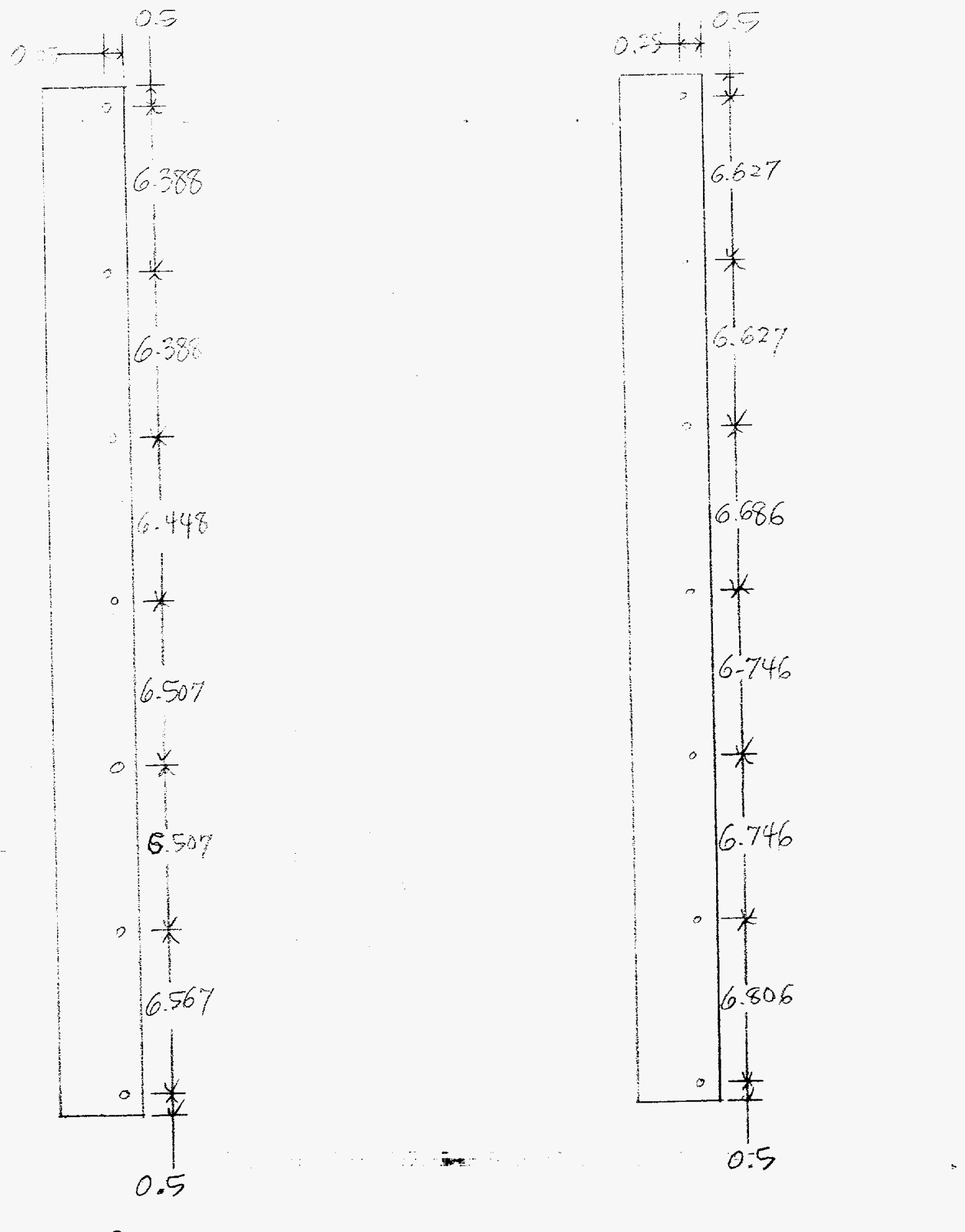

Figure 4.3.6 Side shields. 
INCHES, SCALEIO

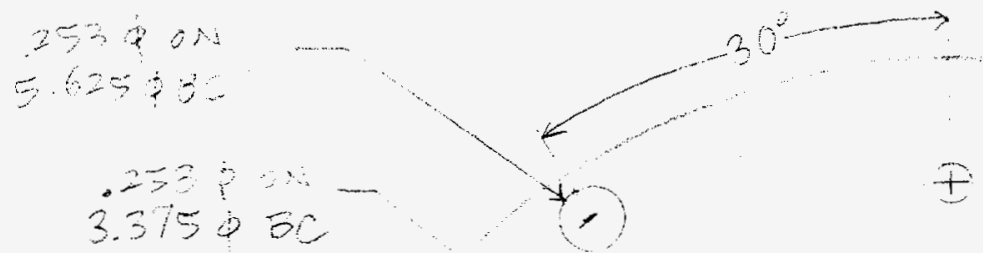

$3 \times 4-40$
CLEARANCE
3.125 BC

80 GINK

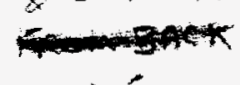

S1DE
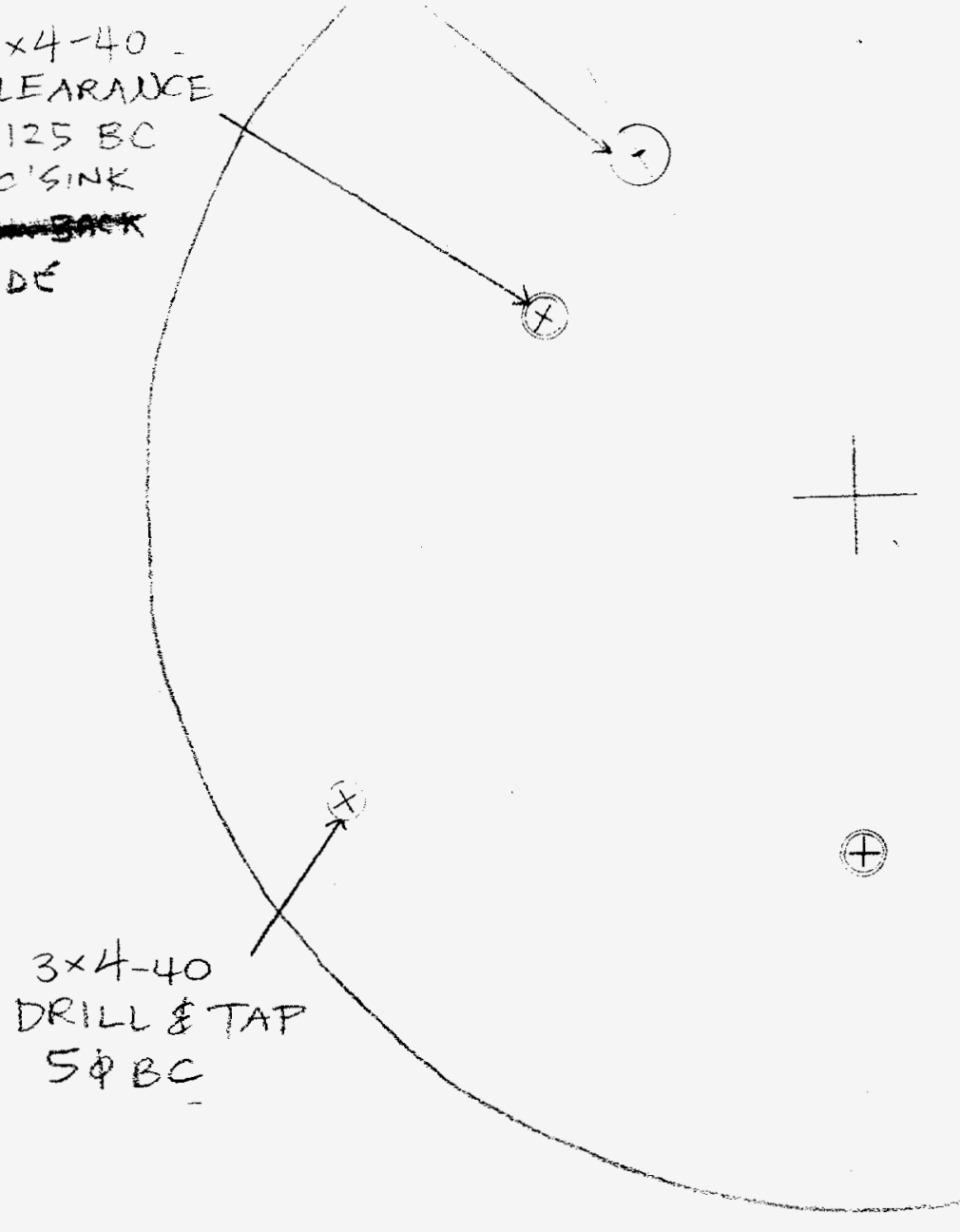

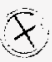
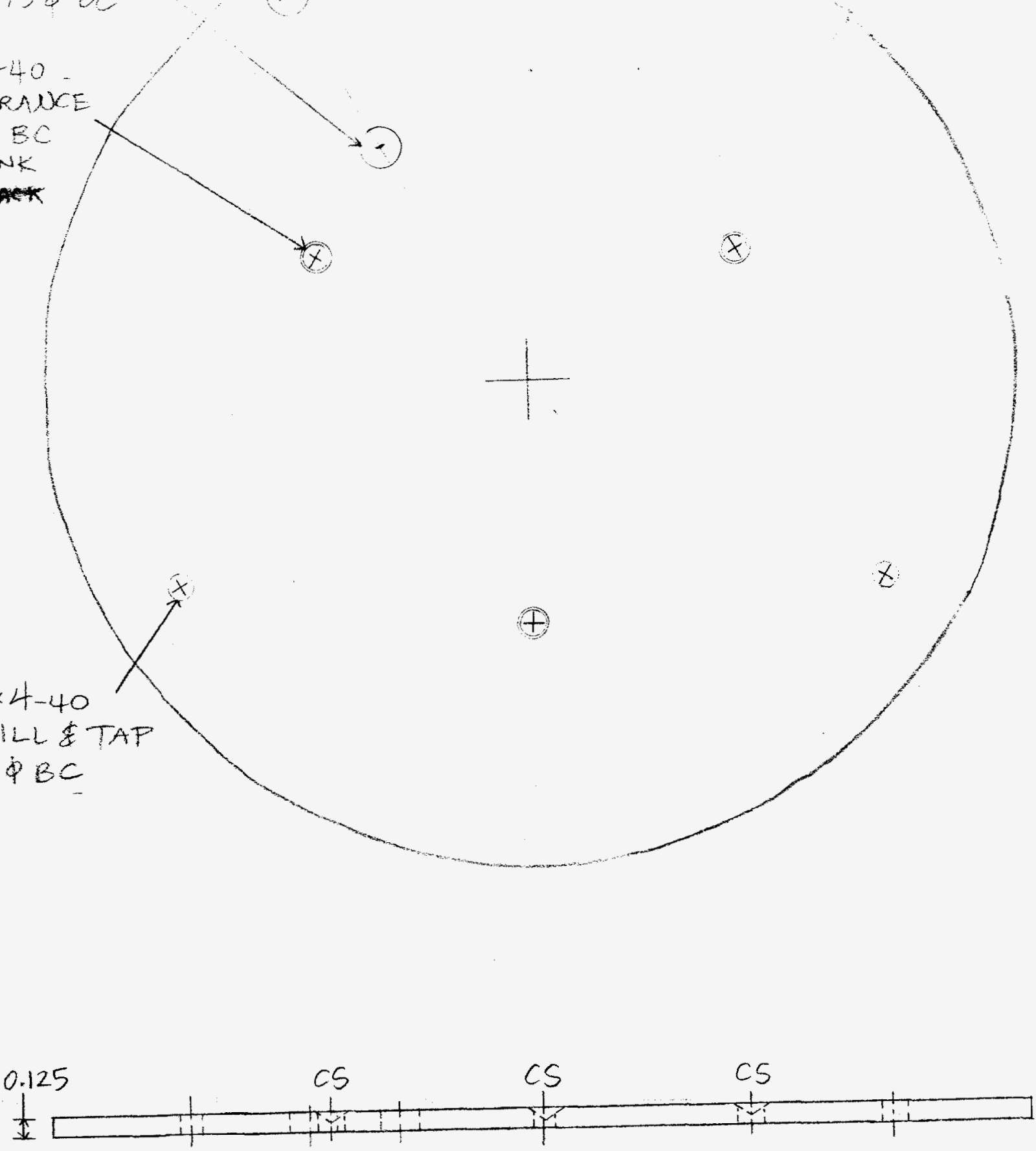

Figure 4.3.7 Lower shields. 

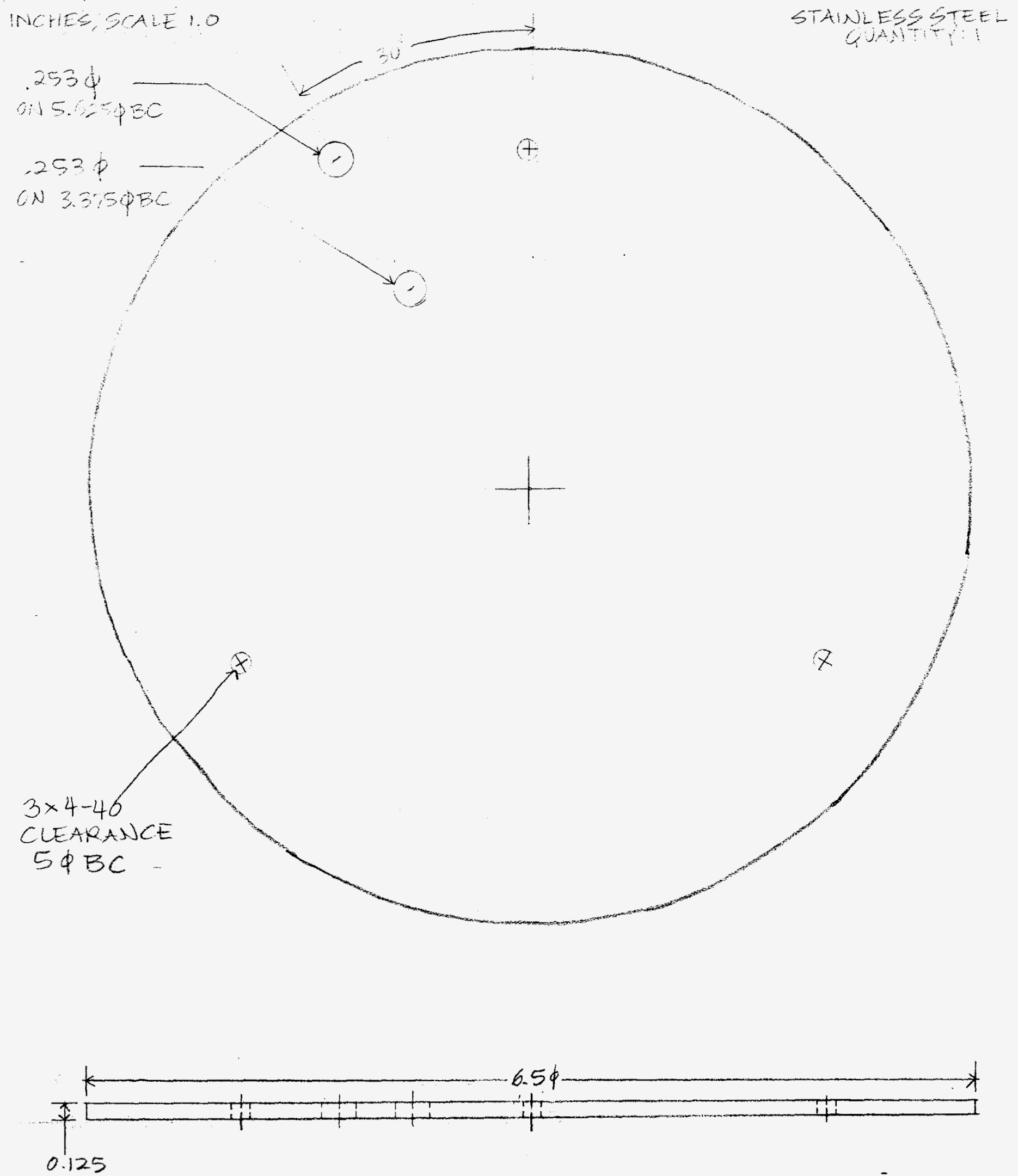

Figure 4.3.8 Lower plate. 
NCHES. SCALE 1.0

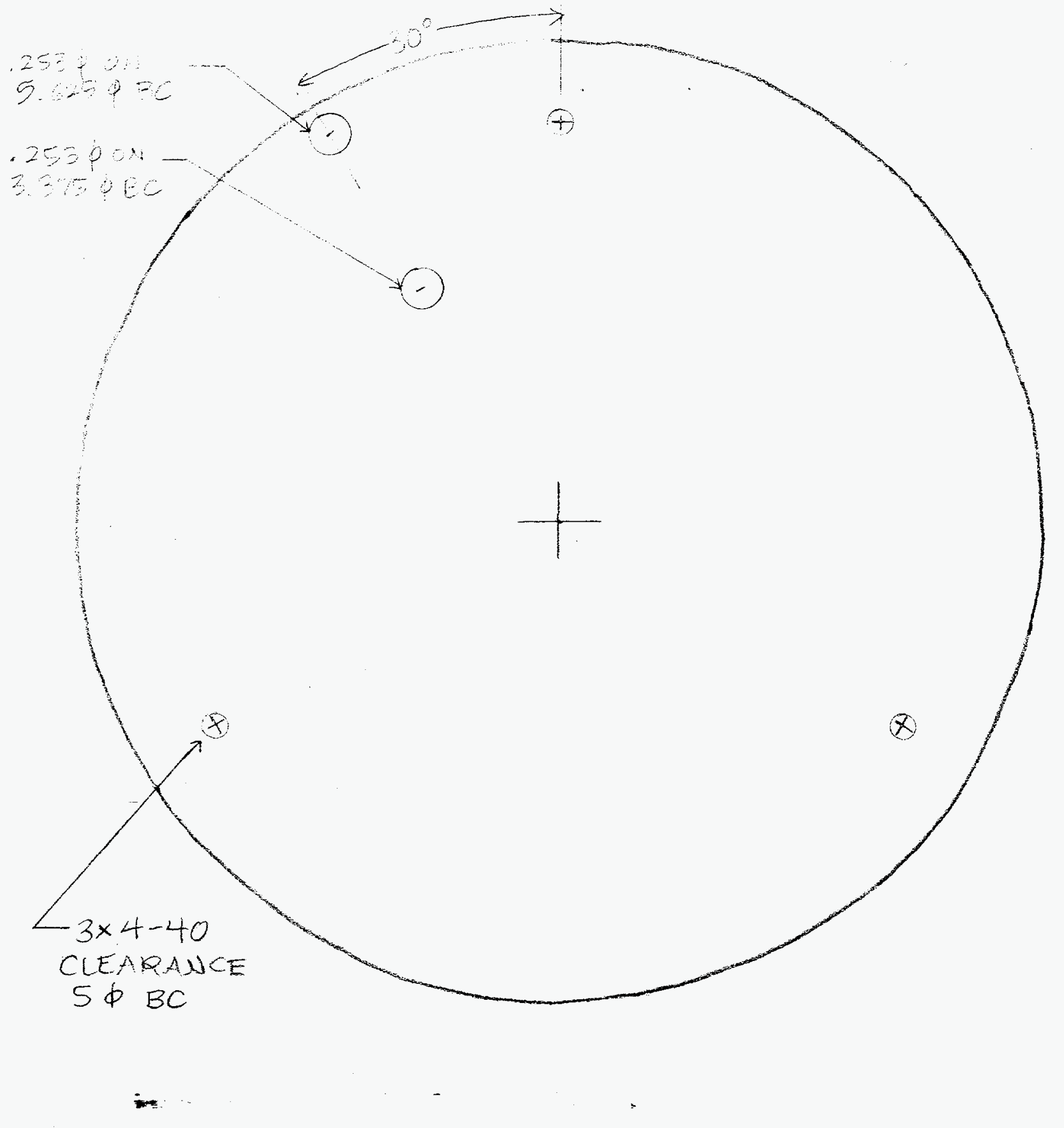

Figure 4.3.9 Upper shields. 
INCHES, SCALE 1.0
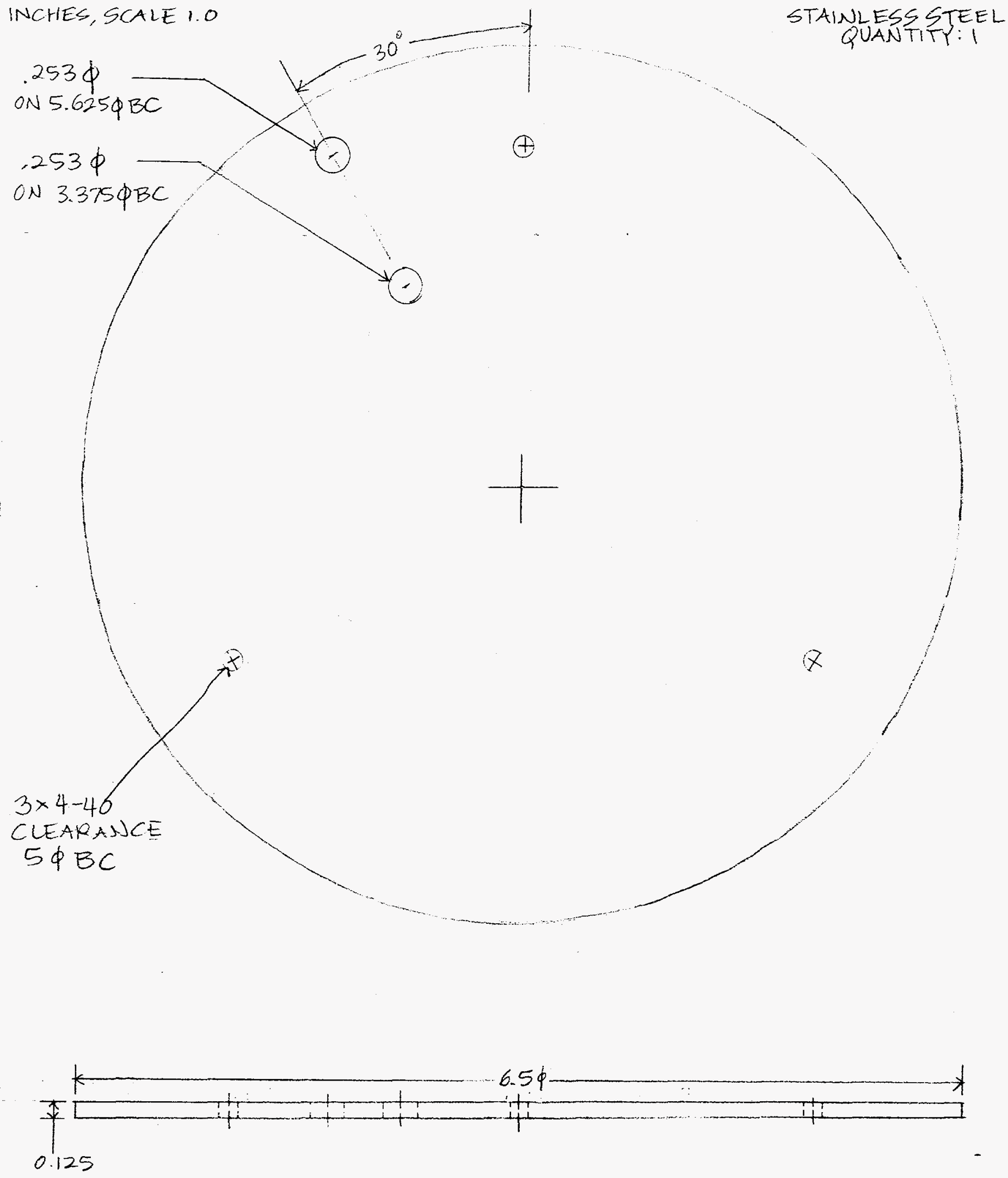

Figure 4.3.10 Upper plate. 

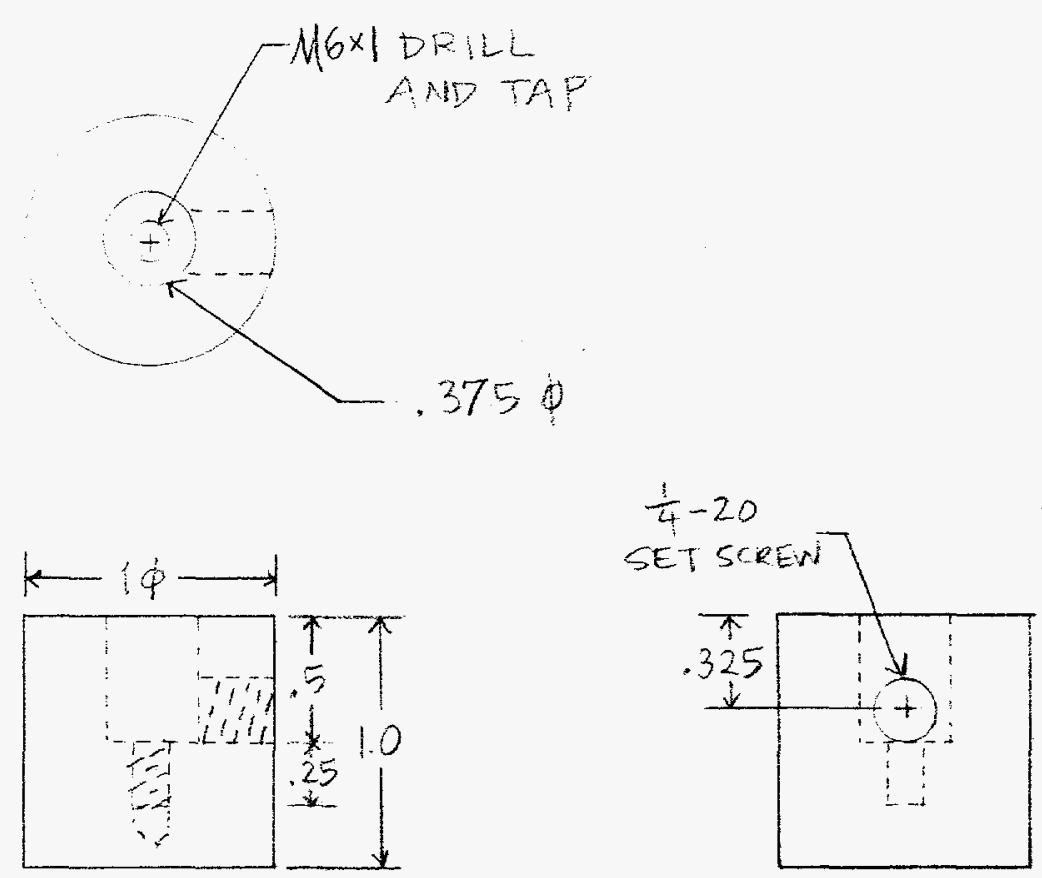

Figure 4.3.11 Coupler. 


\subsection{Design Evolution}

Drawings for the assembly and clamps are shown in chronological order to show the development of the design.

\subsection{Assembly Evolution}

Changes in the assembly were rather gradual, a result of wanting to minimize heat loss.

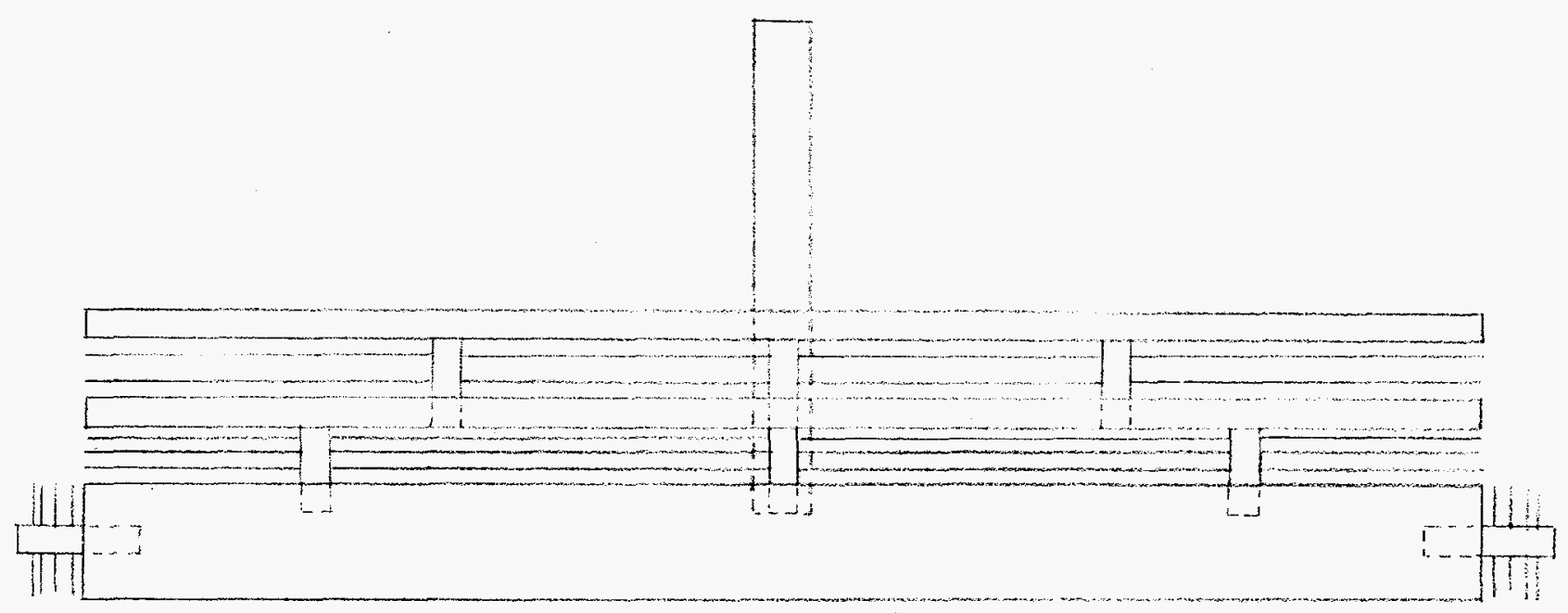

Figure 5.1.1 13 June 1995

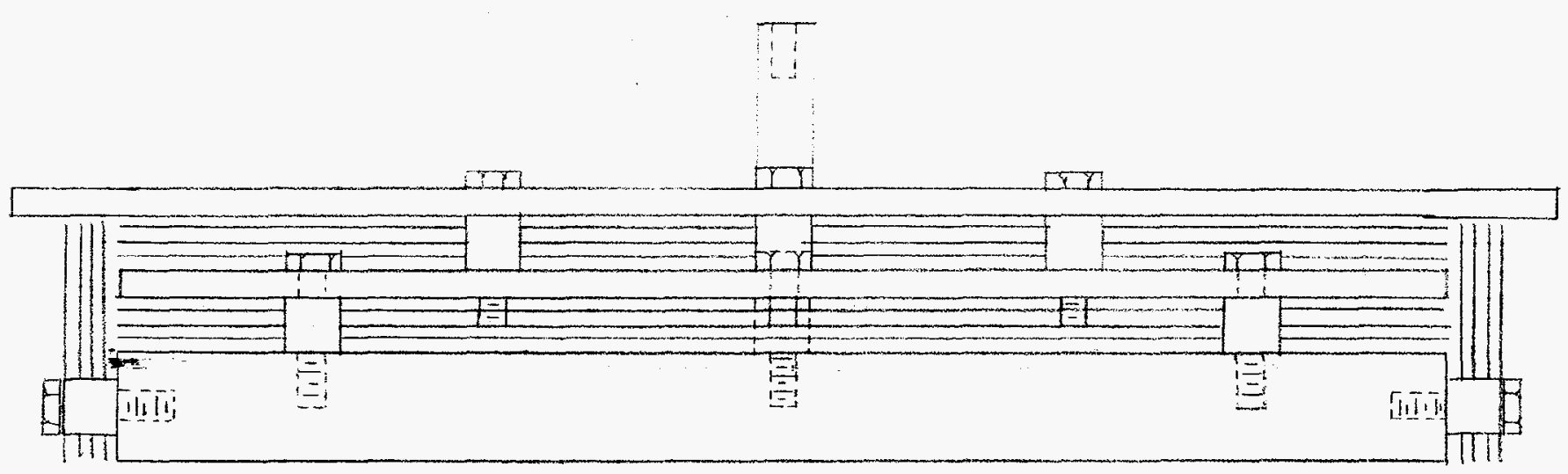

Figure 5.1.2 16 June 1995 


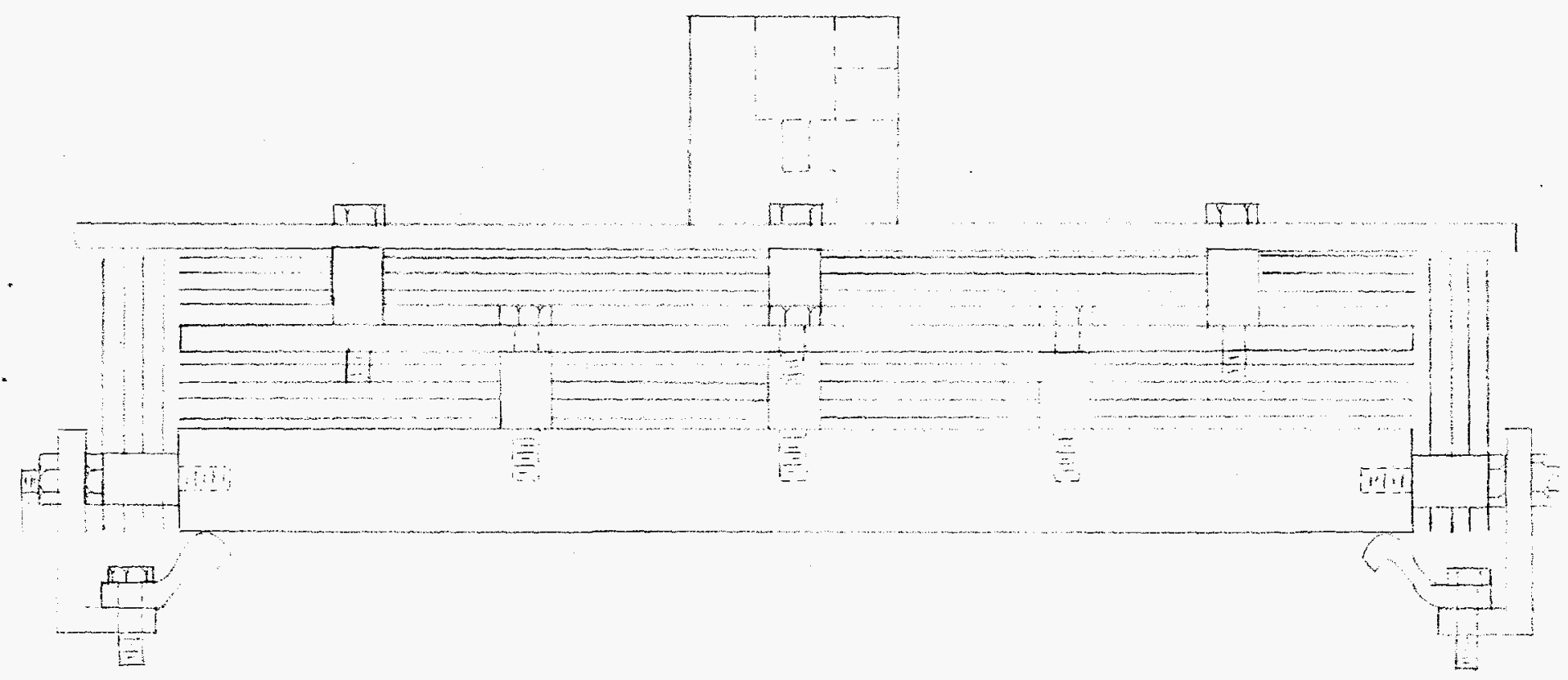

Figure 5.1.3 19 June 1995

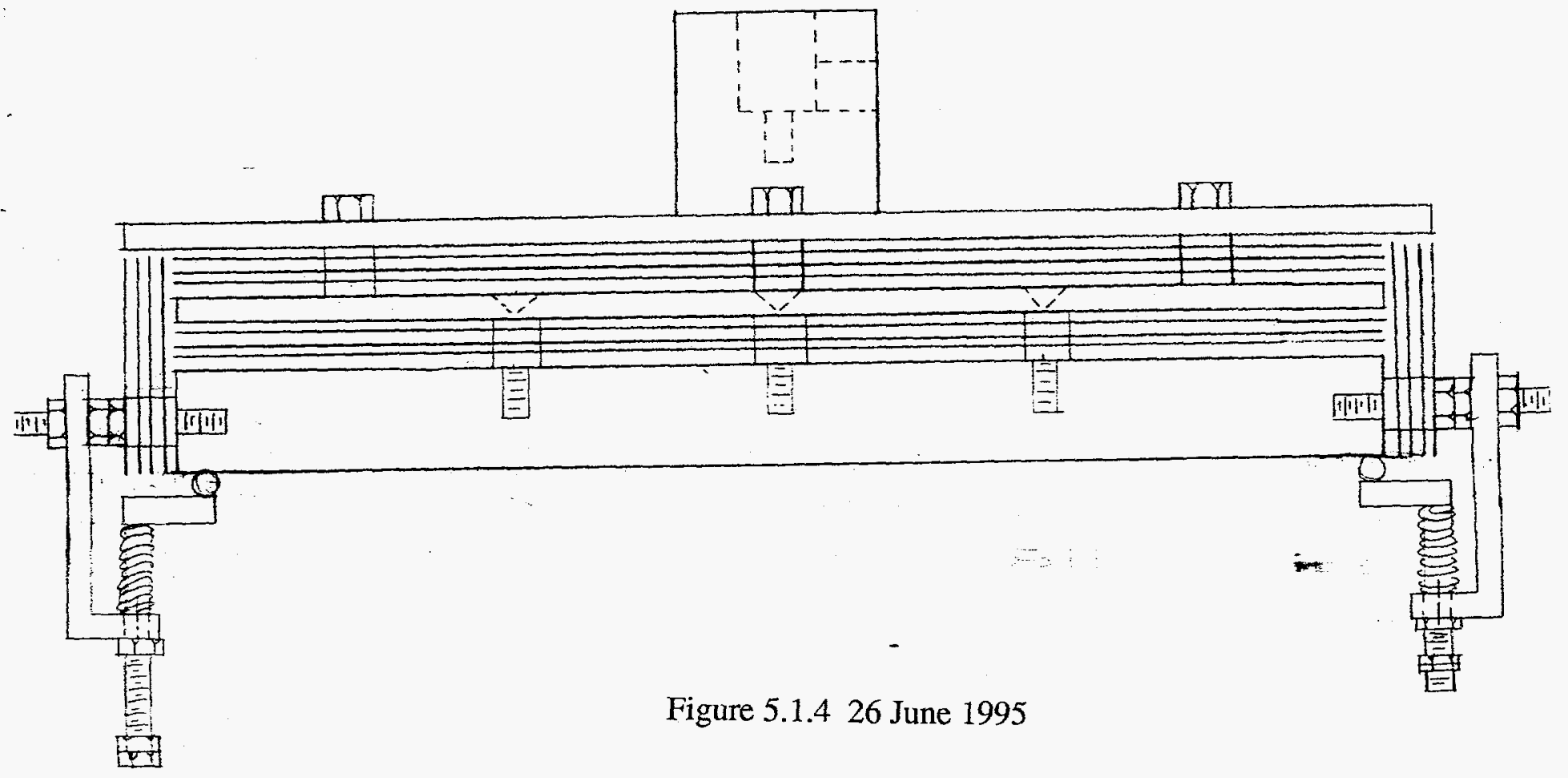




\subsection{Clamp Evolution}

The designing of the clamps was a major challenge. The clamps had to be easy to use, and had to be able to move "out of the way" of the heater. Also, preferably, they would not interfere with the side shields. The following is a sampling of proposed designs, to give an idea of other options for clamps.

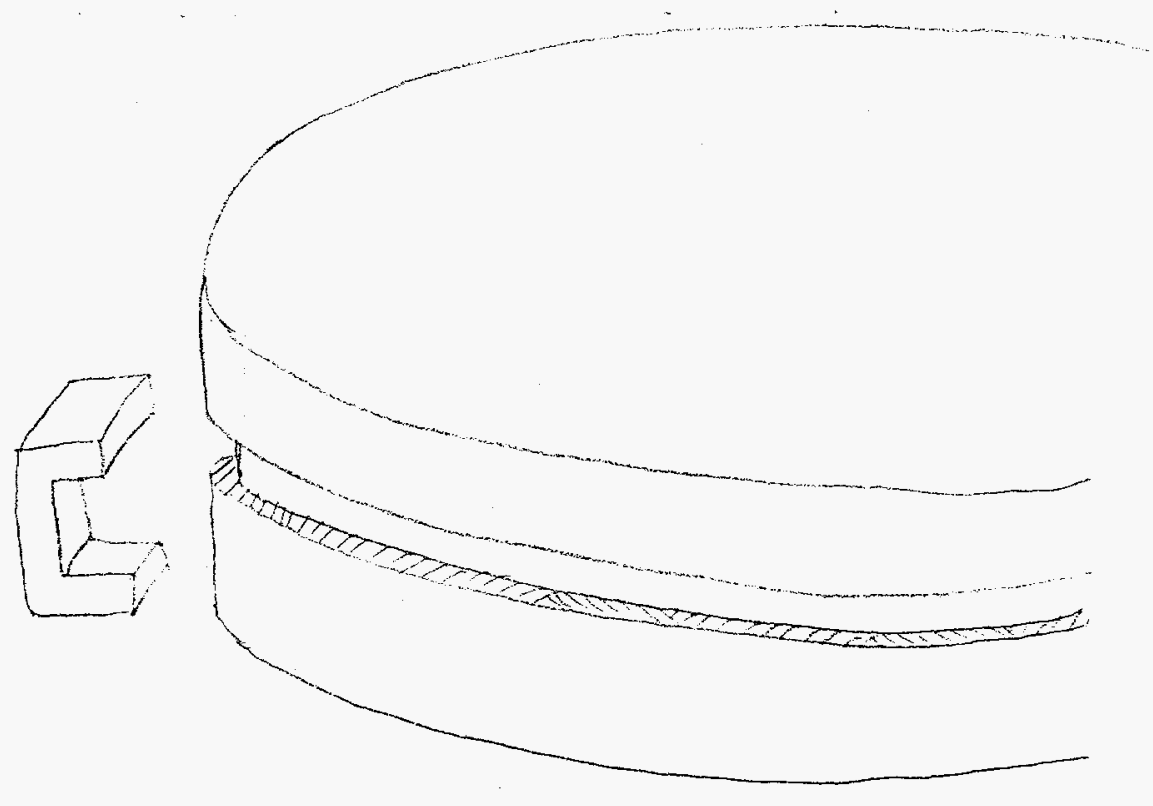

Figure 5.2.1 C clamp.

$$
\text { CLANPING POSTION }
$$
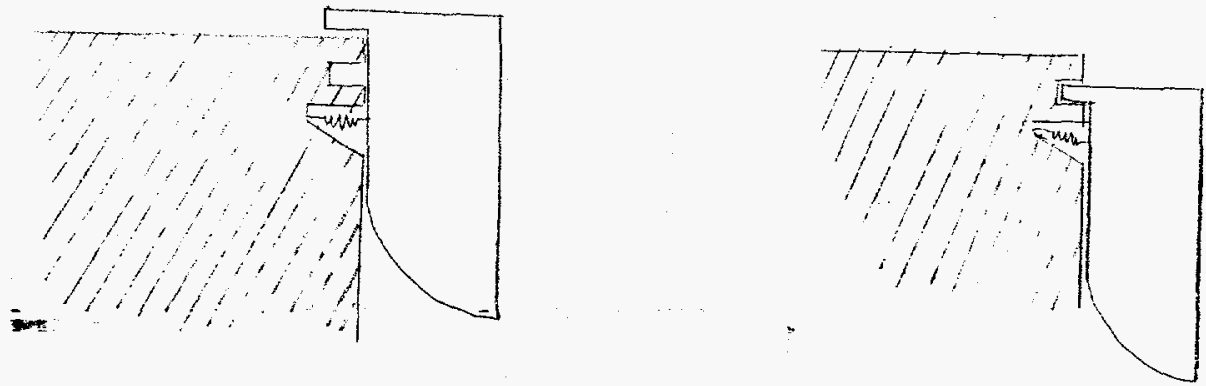

Figure 5.2.2 Spring flange. 


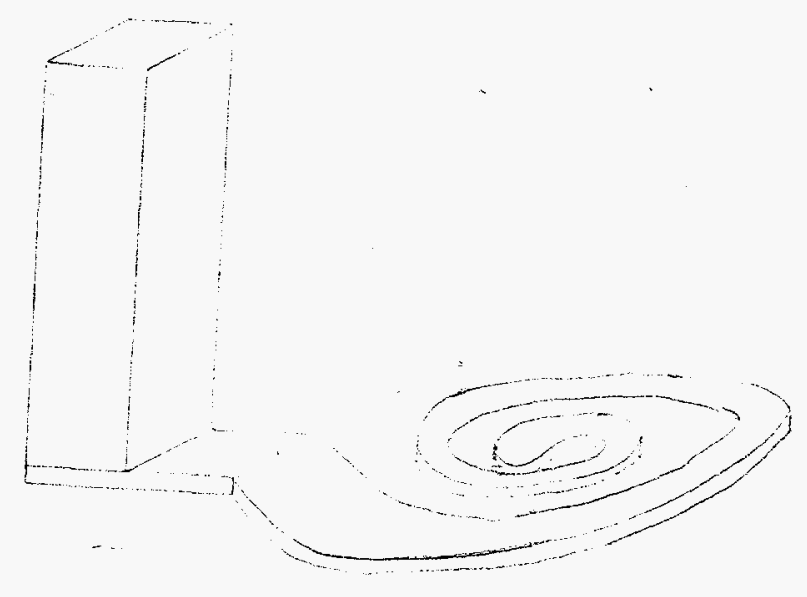

Figure 5.2.3 Swirl clamp.

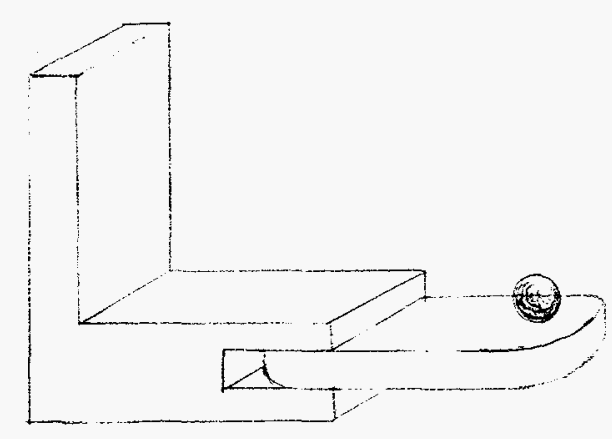

Figure 5.2.4 Fork rotation clamp. 


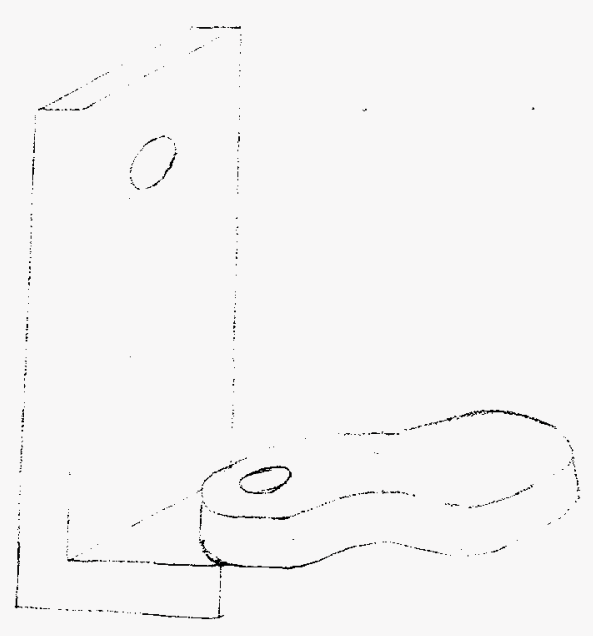

Figure 5.2.5 Smooth surface clamp.

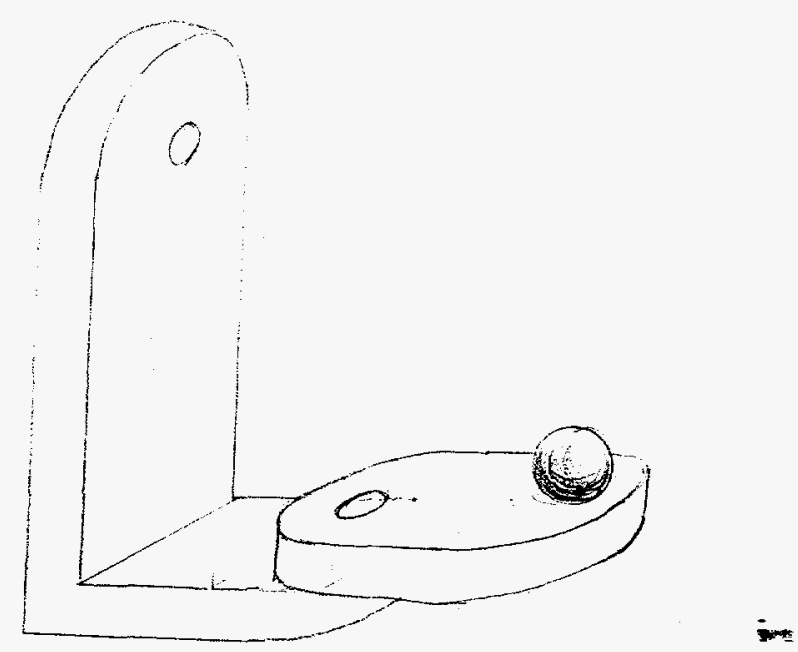

Figure 5.2.6 Rotation clamp. 


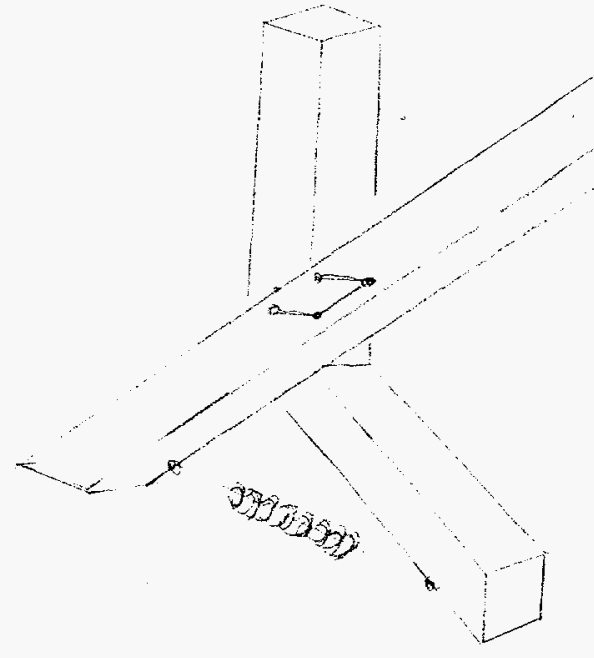

Figure 5.2.7 X-spring clamp.

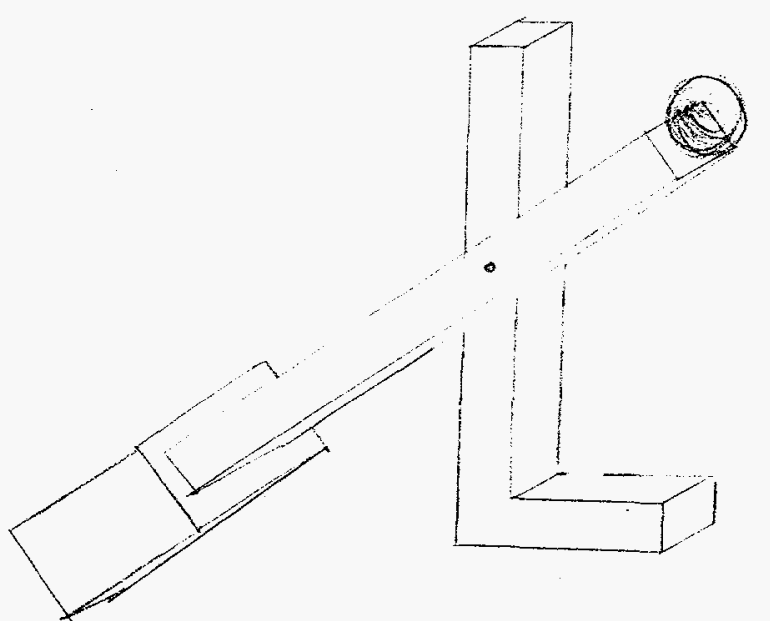

Figure 5.2.8 Counterweight clamp. 


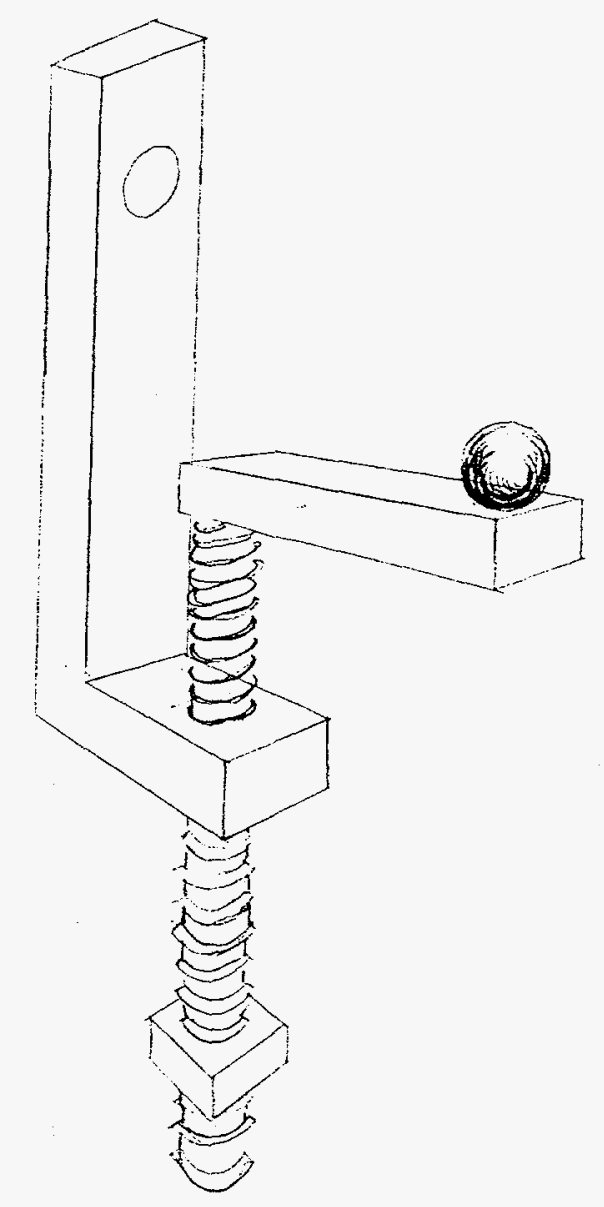

Figure 5.2.9 Spring-rotation clamp.

\subsection{Parts List}

\begin{tabular}{|c|ccccc|}
\hline Part & Material & Quantity & Supplier & Mat'l Cost & Labor Hours \\
\hline Heater body & Stainless steel & 1 & MSC & 50.08 & 18.5 \\
Heater coils & Stainless steel & 2 & Watlow & 180.00 & - \\
Lower shields & Tantalum & 3 & Surplus & -- & 1.5 \\
Lower plate & Stainless steel & 1 & Shop & -- & 1.0 \\
Upper shields & Tantalum & 3 & Surplus & -- & 1.5 \\
Upper plate & Stainless steel & 1 & Shop & - & 1.0 \\
Side shields & Tantalum & 2 & Surplus & - & 3.0 \\
Spacers & Ceramic & 36 & Surplus & - & - \\
4-40 screws & Stainless steel & 12 & Surplus & 4.50 & - \\
Coupler & Stainless steel & 1 & MSC & 1.62 & 3.0 \\
1/8" balls & Stainless steel & 3 & SPI & 0.10 & - \\
Compr. springs & Stainless steel & 3 & Surplus (PIC) & 0.70 & - \\
Welding & - & N/A & ME Shop & - & - \\
Brazing & Nickel Gold & N/A & Braze Shop & -- & - \\
\hline
\end{tabular}

* Costs given per piece. 


\section{References}

1. Cotell, Catherine M., Chrisey, Douglas B., Grabowski, Kenneth S., Sprague, James A., and Gossett, Charles R.: Pulsed Laser Deposition of Hydroxylapatite Thin Films on Ti-6Al-4V. Patent Application.

2. Carslaw, H. S. and Jaeger, J.C.: Conduction of Heat in Solids. Clarendon Press, Oxford, 1959. Page 167.

\section{Milestones}

\begin{tabular}{|c|c|c|c|c|c|c|c|}
\hline & Week 1 & Week 2 & Week 3 & Week 4 & Week 5 & Week 6 & Week 7 \\
\hline & $\begin{array}{l}\text { May } \\
22-26\end{array}$ & $\begin{array}{c}\text { May June } \\
30-2\end{array}$ & $\begin{array}{c}\text { June } \\
5-9\end{array}$ & $\begin{array}{c}\text { June } \\
12-16\end{array}$ & $\begin{array}{c}\text { June } \\
19-23\end{array}$ & $\begin{array}{c}\text { June } \\
26-30\end{array}$ & $\begin{array}{l}\text { July } \\
5-11 \\
\end{array}$ \\
\hline \multirow{7}{*}{$\begin{array}{l}\text { Thermal Modeling } \\
\text { Preliminary sketches } \\
\text { Final design } \\
\text { Detail drawings } \\
\text { Part Ordering } \\
\text { Manufacturing } \\
\text { Design Report }\end{array}$} & $\mathrm{X}$ & $\mathrm{X}$ & $x$ & & & & \\
\hline & & & $\mathrm{X}$ & X & & & \\
\hline & & & & & $x$ & & \\
\hline & & & & & $X$ & $X$ & \\
\hline & & & & & $x$ & $X$ & \\
\hline & & & & & & $X$ & $\mathrm{X}$ \\
\hline & & & & & & $X$ & $x$ \\
\hline
\end{tabular}

